DOI: http://doi.org/10.4038/jrrisl.v100i0.1899

Journal of the Rubber Research Institute of Sri Lanka (2020) 100, 55-68

\title{
The present status and role of the Thurusaviya Rubber Societies in the smallholder rubber sector in Moneragala District: Extension Officers' perception
}

\author{
P K K S Gunarathne*, T M S P K Tennakoon**, Jagath C Edirisinghe***, \\ and K G J P Mahindapala**** \\ * Rubber Research Institute of Sri Lanka, Telewala Road, Ratmalana, Sri Lanka \\ ** Department of Geography, University of Sri Jayewardenepura, Gangodawila, \\ Nugegoda, Sri Lanka \\ *** Department of Agribusiness Management, Faculty of Agriculture and Plantation \\ Management, Wayamba University of Sri Lanka, Makandura, Sri Lanka \\ **** Postgraduate Institute of Agriculture, University of Peradeniya, Sri Lanka
}

\begin{abstract}
The farmer-based organization known Thurusaviya Rubber Societies (TRSs) has been established by the Thurusaviya Fund (TF) for the development of the smallholder rubber sector. This study attempted to assess the present status and role of the TRSs in the smallholder rubber sector in the Moneragala District. The views of 18 Extension Officers (Rubber Development Officers and the two district Coordinating Officers of TF) with over five years of work experience were used to create two focus group discussions by Interpretative Phenomenological Analysis Approach. The perception of the key entities (Organizational structure, Organizational culture, Function of the organization, External environment and Intervention of organizational development) responsible for the development and welfare support for the rubber smallholders was assessed. Data were analysed qualitatively as a case study in Moneragala.

Results revealed, that the majority of TRSs considered in the study were not performing well due to factors such as poor leadership, lack of transparency, lack of enthusiasm of members, lack of trustworthiness, attitudes of members, the role of the Field Officers and changes in the external environment and politics. The contribution from the management unit and the membership was greater in TRSs that were highly active than that of the poorly active TRSs. The self-reliance capacity was low in the majority (99\%) of the TRSs and was highly dependent on Extension Officers involved and the Government's assistance. The majority of TRSs were not goal-oriented and under performing and not dynamic in organizational performances. Hence, extension and development agents feel that critical intervention is required to overcome the above weaknesses. Therefore, organizational development should be done by concerning; goal orientation, need identification, the interaction between Field Officers and TRSs and guiding the TRSs, restructuring of organizations, offering compensation for the management unit, development of physical resources and developing as business entities to achieve their goals and objectives.
\end{abstract}

Key words: Rubber smallholders, Rubber Societies, Thurusaviya Societies 


\section{Introduction}

Rubber smallholders $\quad(<20.2$ ha $)$ is considered the most dynamic segment of the rubber sector as it represents $59 \%$ of the national rubber extent and contributes $48 \%$ to the rubber production in 2019 (MPI, 2019). During the last decade, a considerable increase was observed in the rubber extent due to the adoption of rubber farming by the smallholder farmers in Moneragala District (Wijesuriya et al., 2011). At present, the total extent of rubber smallholdings in Moneragala District is about 5,087 ha and it is the fifth rubber growing District based on land extent under rubber cultivation in Sri Lanka and has 7,802 holdings in number. Three government institutions are functioned to cater to the needs of the rubber smallholder sector in Moneragala; viz. Rubber Development Department (RDD) Thurusaviya Fund (TF) and Rubber Research Institute of Sri Lanka (RRISL). RRISL is responsible for research and development activities, while RDD is responsible for the development of all aspects of the smallholder rubber sector and TF is a supportive agency.

The TF has been established under Act No. 23 in 2000 to uplift the living standards of rubber smallholders by facilitating the production and marketing of quality rubber sheets and ensuring a fair price for their products through the establishment of Farmer Based Organizations (FBOs) called Thurusaviya Rubber Societies (TRSs) (smallholder rubber societies). There are two different layers in the system of TRSs; village-level rubber growers' societies called TRSs and district-level committees. The district-level committee comprises representatives of TRSs and its main role is coordinating between the TF and TRSs. About 85 TRSs are operating in the main rubber growing DS divisions in Moneragala (Table 1). Two District Coordinating Officers of TF (DCOTF) are the grassroots level personnel attached to TF who are responsible for managing the TRSs in Moneragala (http://www.rubberdev.gov. $1 \mathrm{k})$.

Table 1. Thurusaviya rubber societies operating in Moneragala district in each Divisional Secretariat Divisions

\begin{tabular}{lc}
\hline DS division & Number of TRSs \\
\hline Bibila & 04 \\
Moneragala & 12 \\
Medagama & 19 \\
Siyabalanduwa & 03 \\
Madulla & 10 \\
Buttala & 04 \\
Badalkumbura & 29 \\
Wellawaya & 04 \\
Total & $\mathbf{8 5}$ \\
\hline
\end{tabular}

Studies revealed that FBOs could be used effectively in providing multifunctional services to the farmers such as delivering agricultural technologies and inputs, capacity building, assisting in value addition and marketing of products, and also providing welfare facilities (Chamala and Shingi, 1997). However, due to various reasons, these FBOs were unable to produce expected results. Political influences, poor managerial practices, poor monitoring and mistrust between 
management and the member farmers, failing in value addition and establishment of effective market linkages, lack of product diversification are some of the possible reasons for failures (Esham, 2012). However, when it comes to Sri Lanka, it appears that traditional FBOs were unable to deal with the challenges that had faced due to poor leadership, poor attitudes, ideological conflicts of cultural and religious, political influences, structural matters and inefficiencies of relevant government officers (Girragama et al., 1999; Mahindapala et al., 2020 and 2021).

Dissanayake et al., (2003) revealed that these TRSs failed to fulfill their expected organizational goals. In that context, it is important to understand how TRSs behave in the sector as which may give some valuable insights to add the value to smallholder rubber sector. Therefore, studying the organizational behaviour, the management system of TRSs and current issues are important to develop strategies for the organizational development of TRSs. The objective of this study was to examine the organizational role in the smallholder rubber sector in Moneragala District. Finally, it will help to improve the development of the smallholder rubber sector in Moneragala.

\section{Methodology \\ Research approach}

The Interpretative Phenomenological Analysis (IPA) approach was used in this study to collect the data towards the phenomenon being studied. IPA is an approach to qualitative research with an idiographic focus, which means that it aims to offer insights into how a given person, in a given context, makes sense of a given phenomenon (Arnold and Fischer 1994; Morgan and Arcelus, 2009; Petrovici, 2013; Sandberg, 2005). IPA approaches are used in Social Science research to explore how the subject-object dichotomy may be bridged by an interpreter focusing on the context (Farooqa and O'Brien, 2015; Goulding, 2005; Pernecky and Jamal, 2010; Szarycz, 2009). Thus the primary goal of IPA is to investigate how individuals make sense of their experiences. It was assumed that people are 'self-interpreting beings', which means that they are actively engaged in interpreting the events, objects, and people in their lives (Smith and Osborn, 2003; Thompson et al., 1989). According to the codes of Table 3, the interview guide was prepared with the assistance of experts in the smallholder rubber sector. Using the IPA, the overall organizational function of the TRSs which affect the status of rubber smallholders was investigated under the conceptual framework illustrated in Figure 1, based on the literature discussed above. In addition to the FGD, the secondary data published in various reports were also used (document survey) to interpret the results. 


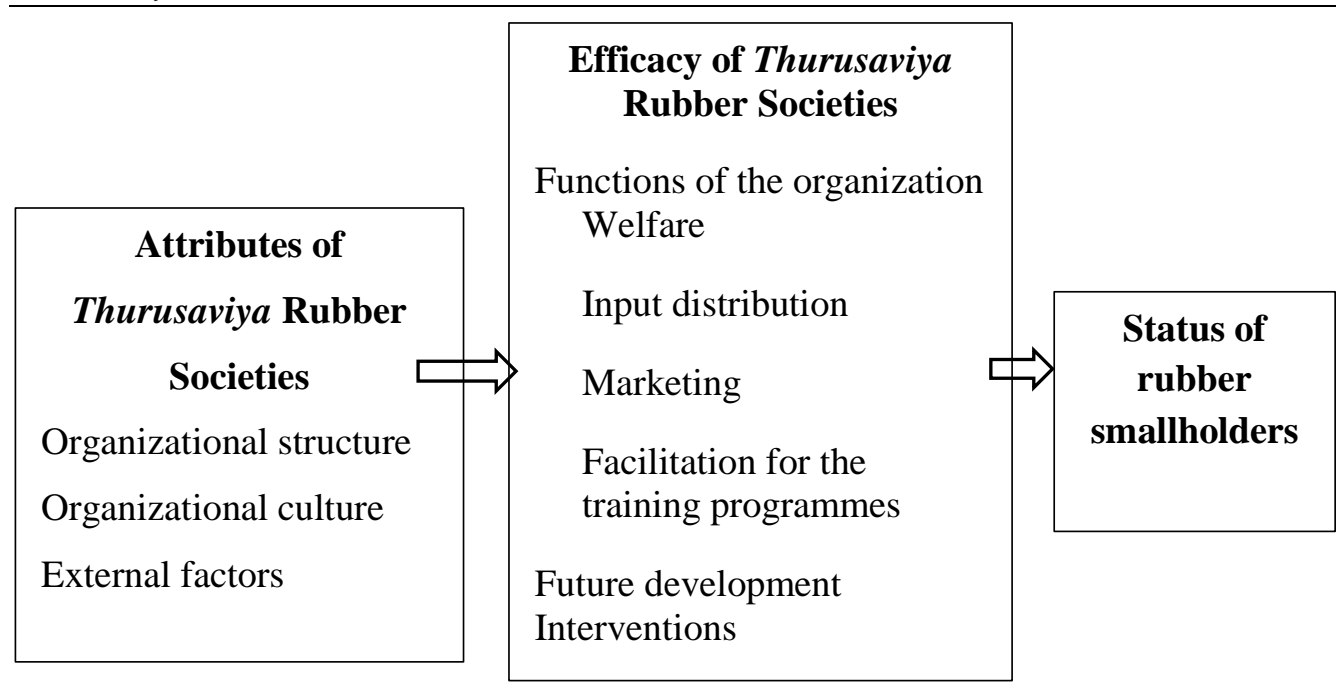

Fig. 1. Conceptual framework

Source: Adopted from the concept of Bohlander and Snell, 2004

\section{Data collection}

Both categories of Field Officers (FOs); Rubber Development Officers (RDOs) who are responsible for the extension activities in the field level attached to RDD and DCOTF are the closest officials to TRSs. Therefore, this study has investigated the role of TRSs through the perception of FOs, based on their experiences. The TRS members and committee members were excluded in the data collection anticipating the possible biasedness. FOs, the research participants belonged to different rubber growing DS divisions of Moneragala, and each of them was assigned for a specific geographical area known as an RDO range. The average number of TRSs in one RDO range was five, ranging from 3 to 7 , based on the density of the smallholders in the respective range.
Data were collected through two Focus Group Discussions (FGDs) using an unstructured interview guide. Among qualitative primary data collection techniques, FGDs have been widely used in agricultural research dealing with a range of extension-related development topics and facilitating an in-depth understanding of certain issues (Morgan and Krueger, 1997). The main advantage of the FGDs is that they allow much more freedom of speech among participants, encouraging them to interact, debate and exchange views during the discussion (Krueger and Casey, 2015). FGDs are conducted with the participation of seven to twelve people to capture their experience and views regarding specific issues closely related to the research objectives. FGDs were moderated by the main author in a manner that adheres to the accepted 
P K K S Gunarathne et al.

guidance related to the particular research strategy given by Bryman, (2012).

FOs were selected for the FGDs purely on a random basis and based on the working experience with a minimum of five years of experience in Moneragala. The total number of respondents was 18 , which is nearly 16 RDOs and two DCOTFs were selected (Table 2). They provide the services for nearly 85 TRSs. Each FGD consists of eight RDOs and one DCOTF. FGDs were held in the local language and were audio-recorded in addition to taking notes.

Table 2. Selected sample of RDOs for the study representing the DS divisions

\begin{tabular}{lcc}
\hline DS division & \multicolumn{2}{c}{$\begin{array}{c}\text { No. of RDOs } \\
\text { participated }\end{array}$} \\
\cline { 2 - 3 } & FGD 1 & FGD 2 \\
\hline Bibila & 1 & 1 \\
Madulla & 1 & 0 \\
Madagama & 1 & 1 \\
Siyabalanduwa & 0 & 1 \\
Moneragala & 1 & 1 \\
Badalkumbura & 2 & 3 \\
Wellawaya & 1 & 0 \\
Buttala & 1 & 1 \\
\hline Total & $\mathbf{8}$ & $\mathbf{8}$ \\
\hline
\end{tabular}

\section{Data analysis}

The audio recorded data were transcribed following the method suggested by Colaizzi (1978). Then a set of codes and categories were developed according to the grounded theory approach as shown in Table 3 and following the method described by Strauss and Corbin (1997). A similar method was adopted by (Mahindapala $e t$ $a l ., 2020)$ to investigate the role of tea smallholding development societies in the tea smallholding sector. The quotes were indicated as $\mathrm{P}_{n} \mathrm{D}_{\mathrm{n}} \quad\left(\mathrm{P}_{\mathrm{n}}=\right.$ Identification number of participant, $\mathrm{D}_{\mathrm{n}}=$ Identification number of FGDs).

\section{Results and Discussion}

According to the view of FOs, around $65 \%$ of the rubber smallholders in Moneragala were members of TRSs. According to the views of FOs, the reasons for not obtaining the membership of TRSs were;

1. TRSs have not been established in areas where rubber lands were dispersed arbitrarily, especially in Bibila, Buttala, Wellawaya and Siyabalanduwa DS divisions,

2. Medium-scale rubber growers were not interested to join the TRSs because of social dignity, and

3. Terminating the membership by themselves of the TRSs due to various matters. Based on the opinion of RDOs, there was variability in the status of activeness of the TRSs in Moneragala. It was revealed that 38 TRSs were entirely 'dormant', where no action has been taken place in the last three years. The relevant quote concerning the above is given below.

"The effort of FOs to reestablish the dormant TRSs was turned out be a failure several times, due to the internal politics within societies and ruthless management practices of the management unit of TRSs" (P5D1). 
Table 3. Perception matrix of Field Officers of the TRSs

\begin{tabular}{ll}
\hline Categories & Codes \\
\hline Structure of the organization & $\begin{array}{l}\text { Structure of the management unit, Decision making, Type } \\
\text { of the membership, Goal orientation }\end{array}$ \\
$\begin{array}{l}\text { Organizational culture } \\
\text { Function of TRSs }\end{array}$ & $\begin{array}{l}\text { Welfare, Input dealing, Marketing, Facilitation for the } \\
\text { training programmes }\end{array}$ \\
External & $\begin{array}{l}\text { Interaction between FOs and TRSs, Political influence, } \\
\text { Environment }\end{array}$ \\
$\begin{array}{l}\text { Organizational development } \\
\text { of TRSs }\end{array}$ & $\begin{array}{l}\text { Restructuring of organizations, Development of physical } \\
\text { resources, Developing as business entities }\end{array}$ \\
\hline
\end{tabular}

Three TRSs under the purview of FOs acted beyond their expectations. Overall, as per their opinion, 43 of TRSs in Monaragala district provide reasonable service to their members. Further, the activeness scale based on a scientific approach should be developed to categorize TRSs as it would help to develop the TRS by solving their specific issues and achieve the expected goals.

\section{Organizational structure of Thurusaviya rubber societies Structure of the management unit}

Organizational structure refers to the framework in which the organization defines how tasks are divided, resources are deployed, and departments are coordinated (Bohlander and Snell, 2004). As per the constitution of TRSs, the Management Unit (MU) comprises 11 volunteer members, including the President, Vice President, Secretary, Assistant Secretary and Treasurer, and six committee members. In the case of highly active TRSs, usually MUs and the majority of the committee members and sometimes even ordinary members were deliberately involved in the management functions. It appeared that the activeness of TRSs greatly depended upon the members in the MU. Although the MU of these TRSs was supposed to meet at regular intervals (usually 2 months), and discuss various issues that affect the members and take decisions, it was revealed in FGDs that the majority of the TRSs were not doing so. The composition of the MU also matters to a great extent to the decision-making of TRSs. Most of the office-bearers of MU were older and retired people (the School Principals, Teachers, Bank Officers) or village leaders who have been holding the post for the previous five to ten years. Usually, most village leaders do not wish to have the younger generation in the MU. This can be identified as the main reason for the non-active nature of the TRSs. The decision-making process in active TRSs was more systematic than the other societies. The used to have regular MU meetings, special meetings address burning issues and annual general meetings conducted at regular time intervals. Thus, active TRSs used proper and active communication channels among members. It was revealed in the following quotes. 
P K K S Gunarathne et al.

"Most of the active societies invited FOs to participate in their regular meetings. If FOs were unable to participate, $M U$ even postponed the particular meeting"(P6D2).

"One of the active societies had a WhatsApp group to share ideas among members. This society had young members in the MU. FOs also linked with this group and shared pieces of advice and views with the society members" (P2D2).

It was also revealed that some TRSs did not have a proper mechanism to conduct annual general meetings. The majority of the FOs in FGDs were of the view that the accounting procedure of these TRSs suffers from lapses such as transparency, incompleteness and mistakes. FOs were not in a position to individually monitor all TRSs as they had other extension tasks. The most serious issue was that those TRSs failed to adopt a transparent auditing procedure in their final accounts and that paved the way to misuse of collective funds. This had affected the membership morale and engagement of societal activities. One of the Field Officers explained his view in the following quote.

"One of the Presidents and a Treasurer of society had used society funds for personal affairs. Members couldn't recover the misused funds from both these persons. It had generated a bad attitude on the society and finally it was collapsed" (P3D1)
Both full-time and part-time rubber smallholders were members of the TRSs. As per the general understanding of the FOs, the youth involvement had been at a moderate level in both categories. The majority of the FOs argued in the following way:

"Full-time farmers fully engaged in rubber cultivation-related practices and their preparedness in TRSs activities was high as it was a part of their livelihood strategies. With the part-time rubber smallholders, they may be employers or self-employed and have to engage in many activities and therefore, they did not have time to spend for TRSs activities" (P2D1)

Because of that, FOs and MU faced difficulties when distributing limited subsidized resources among the members. Many members argued that priority should be given to the active members, except for 12 TRSs, where the majority of the members were women. One of the reasons for the higher participation of females was that most males are unable to participate in meetings of TRSs during the daytime. Sometimes, the registered rubber smallholders do not participate in meetings of TRSs, but their children tend to participate in these unless their registration is canceled. The following quote is about the memberships, as stated by the respondents.

"However, under normal
circumstances, the level of
participation did not exceed 50\% of
the total membership. But in the 
subsidy distribution period, the participation was more than $80 \%$. However, attitude on the MU by the members was also effecting the participation in societal activities" (P6D1).

"Although most of members were not in an active state in societies, they maintained their membership as it is a requirement to receive subsidies from TF." (P5D2).

Except for a very few TRSs, the majority of the societies had not set a goal/target to be achieved and no activity plan had developed. However, TF had some targets and had prepared a common activity plan common for the whole country. Therefore it should be changed and developed according to individual societies. Yet, this situation should be changed by the training of MU. Participatory and need-based activity plans should be developed for each society with the assistance of the FOs and the district committee. Implementation of extension programs should be based on their own needs. Therefore, TRSs maintain good interaction with the FOs. On the other hand, the majority of the FOs were of the view that some societies were established solely to capture Government aids. The relevant quote by the respondents is stated below.

"Some societies were created only to obtain a subsidy for the smokehouses, coagulate cups and trays and rollers for rubber processing, while they were not keen enough to arrange any extension and welfare programme in order to achieve the development of rubber farming" (P1D1)

Nevertheless, in a few TRSs close to the urban areas, there were no such factors (subsidies) taken into consideration in the development of their societies. Therefore, TF should make policies attract young and energetic generation into the MU by facilitating with attractive allowances, due recognition and conducting human resource development programmes for the members of MU.

\section{Organizational culture of Thurusaviya rubber societies}

Organizational culture is defined that a system of shared meaning held by members that distinguish the organization from other organizations (Bohlander and Snell, 2004). The role of leadership plays a key role to influence people towards the attainment of organizational goals. Therefore, leadership qualities and role of MU is the most crucial factor highlighted in discussions as TRS is FBO. The active and successful TRSs represent the multitalented and skilled leaders in MU. They always tried to achieve their organizational goals effectively and efficiently. It was described by many respondents as in the following quote. "Not only the input distribution
programmes under the subsidy, but
also in other programmes (extension,
welfare and marketing), effective
leaders promptly involve and
accomplish the basic requirements of 
P K K S Gunarathne et al.

programmes in an efficient and in a transparent manner" (P8D2)

With the poor leadership traits of MU, there were many conflicts arisen among the members of the MU and also the members and MU. It would be affected the effectiveness and efficiency of TRSs. The relevant quote by a participant is given below.

"Two of my eight TRSs had been performing well under a good leadership, whilst the rest were not. Because of that the members were not participating even in the annual general meeting and not paying membership fees" (P4D1)

Some members of MU who have personal issues with member groups would treat the particular group differently, and that affects the organizational commitment as stated in the quote below.

"One of the Presidents always tried to facilitate his neighbours and close relatives and this society is now under dormant condition" (P9D1)

Thus, a FO pointed out that;

"TRSs especially located in remote areas or when most of the rubber smallholders were not well-educated or due to both of reasons, members with respectful characters were in the top positions of the MU. Because of that situation, "The president and the Secretary of that TRSs were suspects for misuse of funds and distribution of subsidized inputs among members was not done in the proper way. However, no one is going to question. On the other hand, they did not have an idea about their misuse also" (P8D1).

Although the majority of the members in MU comprised of female members, there were no issues related to gender in the management of TRSs. There were no specific relations with gender and management with respect to the activeness of the committee and the society. According to the respondents, trustworthiness and transparency were the essential characters of the members of MU. They were required to maintain trust in their actions and it helped to develop a favourable relationship between all stakeholders (the MU, FOs and the members) as it was necessary to have good interactions with each category.

\section{The function of Thurusaviya rubber societies}

The major functions of TRSs were, subsidized input distribution, developing the marketing facilities, organizing the training programmes for members for the rubber farming and welfare activities. As revealed in the FGDs, the training programmes organized by MU were poor in most societies. FOs had targets to conduct training programmes for rubber farming, yet, it was difficult to organize training programmes with most of TRSs. TRSs do not identify the importance of the technology transfer programmes whilst they always tried to implement subsidy disbursement programmes. It seemed that a hidden objective of the establishment of some of the TRSs was 
just to acquire the benefits given by the Government as explained by respondents in the following quote

"All the TRSs were highly concerned about the benefits and subsidies that are given by the Government. Those who have left the society will be rejoined when the Government introduces a beneficiary program (GPCs and rubber rollers) again. Most of the society members perceived that the technical knowledge had less value than those physical and financial inputs. Rubber smallholders were highly addicted to the subsidy and seek subsidies for every aspect. It was a dependency mentality, developed over the decades through the policies that have been adopted" (P7D1).

Carrying out a decent welfare system promotes the group dynamics within the TRSs, people were encouraged to attract to the TRSs, which leads to strengthen the activities of TRSs. Most of the TRSs were given less priority to promote welfare activities due to various reasons; lack of initial funds, management not being in the position to initiate welfare projects, and presence of many specific welfare societies at village-level. However, a few societies started successful programmes as stated in the quote below.

"One society had a well-functioned money lending system. The interest rate of these societies which was comparatively low compared to other micro-finance institutions in the village. They had a separate act for the loan scheme and not only that, gifts (books and toys) were given to the children of members at the end of every year by using profits of the society" (P4D2)

The major function of the TRSs was to strengthen the rubber marketing system in the village level rubber smallholders. To achieve this objective, 28 TRSs had established Group Processing Centers (GPCs). Rubber smallholders who don't have rubber processing facilities can use these centers to produce quality sheet rubber. This product was sold in bulk at a high price. The most of GPCs have functioned well and achieved their targets. There were many successful cases of TRSs as mentioned by FOs and as a summary;

"Many advantages were achieved by the establishment of GPCs, low sheet production cost, high-quality sheet production, time-saving for rubber smallholders, enhancement of the activeness and group cohesiveness in the society" (P3D2).

A few of the FOs highlighted the issues of GPCs; viz.

1. There was a trend that rubber smallholders opt to purchase their processing equipment such as rollers and smokehouses. Therefore, they did not want the facilities of GPCs. This led to discontinuation of the functions of GPCs, as the capacity of the smokehouse could not be fulfilled,

2. Difficulty inmanaging the maintenance cost and 
3. Non-stability of marketing channels. According to the above discussion, most of TRSs were not focused on their major role at the village level.

\section{External environment}

This section explains how FOs recognized TRSs' response against the external factors/effects. It was revealed that all the TRSs were highly sensitive to external support in relation to extension activities and forms of subsidies. FOs guide the TRSs on different occasions, such as the time of the election of office bearers, organizing the extension programmes and financial matters. If there was a burning issue, meeting with the MU of each TRSs was taken under FOs purview. RRISL gets direct support from the TRSs for their technology transfer programmes and research purposes. There were a few active TRSs that effectively utilized RDD and RRISL to bridge their knowledge gap. On the other hand, TRSs gave their reasonable support for RRISL and RDD in every aspect as evident from respondents according to the following quote.

"I had only one active society under my purview, and they come up with some topics and requested me to conduct training programmes such as agronomy, tapping and processing of rubber. Not only that, one training programme on tapping skill development was arranged by themselves by directly contacting RRISL" (P2D2).
Rubber sheet and latex collectors had requested TRSs to strengthen the rubber marketing channel. It helped to get a marketing commission into the TRSs. Concerning the political influence, there were differences in opinion based on the locality. Some FOs had expressed that political influences were affecting TRSs' affairs especially in the distribution of rollers. One of the major roles of FOs was the development of TRSs. The opinion of all FOs was that TRSs were not independent organizations but they mainly depend on FOs in the particular region. As per the discussions, they were not sure about their strength and always seek help from FOs. It appeared that reasonably independent TRSs were quite rare and even not common among TRSs. However, two TRSs were identified with acceptable qualities as stated below.

"TRSs were mostly independent of the FOs. They conducted monthly meetings on their wish. FOs participate when a serious issue has occurred and in annual general meeting only" (P8D2).

The majority of the FOs had expressed that they would like to see TRSs running as independent societies. All FOs had accepted that they need the support of TRSs in their extension and development activities in the rubber sector as they cannot reach many rubber smallholders.

\section{Organizational development of Thurusaviya rubber societies}

The various drawbacks with regard to the TRSs had been explored previously under different categories. This section 
attempted to gather the FOs suggestions and views to overcome those weaknesses and organizational development. Most FOs $(96 \%)$ were of the view that the present framework as a voluntary organisation had to be changed. They argued that these TRSs could not be survive in the current competitive world as an entirely voluntary organisation. However, most of them express that it was necessary to study the structure of a similar organisation operating in different sectors in Sri Lanka and the world. Then the best model should be developed and adopted. Most of them have expressed that;

1. It was also necessary to change the mindset of rubber smallholders as they have lost their faith on TRSs,

2. Right people should be appointed to the leadership of the society,

3. To offer an allowance for the members of MUs to recognize their service and compensate for their time involvement,

4. Improving the physical resource pool (instruments of land preparation and equipment for tapping panel marking, ICTs facilities),

5. TRSs should be developed as a business entity by manufacturing various rubber-based products such as rubber bands and automotive accessories.

\section{Conclusion}

The study revealed that the majority of TRSs were not performing well due to certain internal and external factors. Internal factors were identified as poor leadership, lack of enthusiasm of members, issues in trustworthiness, transparency and attitudes of the members, while external factors were Government assistance, the role of the extension agent, changes in the external environment, the effect of other organisations and politics. TRSs were poor as they mainly depend on FOs and are highly sensitive to government aids. The majority of TRSs were not goaloriented. From the extension and business perspectives, the majority of TRSs were not dynamic in organisational performances. The study suggests the necessity of interventions to address the above weaknesses under the organizational development perspective.

\section{Limitation and direction for future research work}

Only the FOs were used to collect the data on the assumption that they were impartial and none of the TRSs members were considered. Therefore, the findings of the study may be subjected to confirmation by another study.

\section{Acknowledgement}

The authors are grateful to the District Coordinating Officers of Thurusaviya Fund and Rubber Development Officers of Rubber Development Department in Moneragala District for their valuable support.

\section{References}

Arnold, S and Fischer, E (1994). Hermeneutics and consumer research. Journal of Consumer Research 21(1), pp.55-70.

Bohlander, G and Snell, S (2004). Managing Human Resources. $13^{\text {th }}$ edition. pp.232274, Thomson Corporation, USA. 
Bryman, A (2012). Social Research Methods. pp.416-428. Oxford University Press.

Chamala, S and Shingi, P M (1997). Establishing and Strengthening Farmer Organizations: A Reference Manual FAO (Eds. B E Swanson), pp. 212. Daya Publishing House New Delhi.

Colaizzi, P (1978). Psychological research as the phenomenologists views it. In: Existential Phenomenological Alternatives for Psychology. pp.48-71. (Eds. R S Valle and M King) New York Oxford University Press.

Dissanayake, D M A P, Wijesuriya, Wasana, Herath, H M L K, Wijeratne, Mahinda, Edirisinghe, $\mathrm{J} \mathrm{C}$ and Abeywardene, Vidura (2003). Development of the rubber sector through participatory interactions: smallholders' perception on the Thurusaviya programme and suggestions for improvement. Interaction between the Environment, Society and Technology (INTEREST), Partner 5: Rubber Research Institute of Sri Lanka. pp.113.Rothamsted Research, Harpenden, UK.

Esham, M (2012). Lesson for Farmer base Organizations (FBO) in Sri Lanka experiences from agriculture cooperative (JA) in Japan. A Journey in harmony sixty years of Japan - Sri Lanka Relations (Ed. H D Karunaratne).pp 415.

Farooqa, S and O'Brien, C (2015). An action research methodology for manufacturing technology selection: a supply chain perspective. Production Planning \& Control 26(6), pp. 467-488.

Giragama,W M G B, Sanker, S G and Samarakoon, S M A (1999). Development and Strengthening of Farmer Organizations through Farmer Convention. Final Evaluation Report, Hector Kobbekaduwa Agrarian and Research and Training Institute, pp 103.
Goulding, C (2005). Grounded theory, ethnography and phenomenology: a comparative analysis of three qualitative strategies for marketing research. European Journal of Marketing 39(3/4), pp.294-308.

Krueger, R A and Casey, M A (2015). Focus Groups: A Practical Guide for Applied Research, $5^{\text {th }}$ ed.; SAGE Publications, Inc.: Thousand Oaks, CA, USA, 2015; ISBN 9781412969475, pp 127-138.

Mahindapala, K G J P, Jayathilaka, M W A $\mathrm{P}$, Jayawardane, $\mathrm{L} \quad \mathrm{N} A \mathrm{C}$, Kopiyawattage, K P P and De Mel, M P M (2020). Role and capacity of Tea Societies in the smallholding sector in Sri Lanka: An assessment based on the perceptions of Extension Officers. Tropical Agricultural Research 31(1), 43-55. DOI: http://doi.org/10.4038/tar. v31i1.8343.

Mahindapala, K G J P, Jayathilaka, M W A $\mathrm{P}$, Jayawardana, L N A C and Sivananthawerl, T (2021). Developing an assessment frame for Tea Sector farmer organizations based on opinions of agriculture extension personnel. Tropical Agricultural Research 32(2), 135-145. DOI: http://doi.org/10.4038/tar.v32i2.84 61.

Ministry of Plantation Industries. (2019). Plantation Sector Statistical Pocket Book, Sri Lanka. pp100-150.

Morgan, D, Krueger, R (1997). The Focus Group Kit. SAGE Publications, Inc.: Thousand Oaks, CA, USA, 1997; ISBN 9780761907602.pp 278.

Morgan, J F and Arcelus, J (2009). Body image in gay and straight men: A qualitative study. European Eating Disorders Review 17(6), 435-443. doi: 10.1002/erv.955.

Pernecky, T and Jamal, T (2010). (Hermeneutic) phenomenology in tourism studies. Annals of Tourism Research 37(4), 1055-1075. 
Petrovici, I (2013). Philosophy as hermeneutics. The world of the text concept in Paul Ricoeur's hermeneutics. Social and Behavioral Sciences 71, pp.21-27.

Sandberg, J (2005). How do we justify knowledge produced within interpretive paradigms? Organisational Research Methods 8(1), pp.41-68.

Smith, J A and Osborn, M (2003) Interpretative phenomenological analysis. In: Qualitative Psychology: A Practical Guide to Research Methods. (Ed. J.A. Smith), London, Sage.pages

Strauss, A and Corbin, J M (1997). Grounded theory in practice, Thousand Oaks, CA: Sage. pp 108-213.

Szarycz, G S (2009). Some issues in tourism research phenomenology: A commentary. Current Issues in Tourism 12(1), 47-58.
Thompson, C J, Locander, W B and Pollio, H R (1989). Putting consumer research back into consumer behaviour: The philosophy and method of existential phenomenology. Journal of Consumer Research 16(2), 133-146.

Wijesuriya,W, Dissanayake, D M A P, Herath, H M L K and Gunarathne, P K K $S$ (2011). Constraints in sustainable smallholder rubber farming in the Moneragala district: Journal of the Rubber Research Institute of Sri Lanka 91, 61-73.

Address for correspondence: $\mathrm{Mr} \mathrm{P} \mathrm{K}$ K S Gunarathne, Advisory Officer, Advisory Services Dept., Rubber Research Institute of Sri Lanka, Telewala Road, Ratmalana, Sri Lanka.

e-mail:kapila.s.gunarathne@gmail.com 